University of Nebraska - Lincoln

DigitalCommons@University of Nebraska - Lincoln

2012

\title{
Magnetism of directly ordered Sm-Co clusters
}

\author{
Balamurugan Balasubramanian \\ University of Nebraska-Lincoln, balamurugan@unl.edu \\ Ralph Skomski \\ University of Nebraska-Lincoln, rskomski2@unl.edu \\ Xingzhong $\mathrm{Li}$ \\ University of Nebraska - Lincoln, xli2@unl.edu \\ George C. Hadjipanayis \\ University of Delaware, hadji@udel.edu \\ David J. Sellmyer \\ University of Nebraska-Lincoln, dsellmyer@unl.edu
}

Follow this and additional works at: https://digitalcommons.unl.edu/physicssellmyer

Part of the Physics Commons

Balasubramanian, Balamurugan; Skomski, Ralph; Li, Xingzhong; Hadjipanayis, George C.; and Sellmyer, David J., "Magnetism of directly ordered Sm-Co clusters" (2012). David Sellmyer Publications. 231. https://digitalcommons.unl.edu/physicssellmyer/231

This Article is brought to you for free and open access by the Research Papers in Physics and Astronomy at DigitalCommons@University of Nebraska - Lincoln. It has been accepted for inclusion in David Sellmyer Publications by an authorized administrator of DigitalCommons@University of Nebraska - Lincoln. 


\title{
Magnetism of directly ordered Sm-Co clusters
}

\author{
B. Balamurugan, ${ }^{1,2, a)}$ R. Skomski, ${ }^{1,2}$ X. Z. Li, ${ }^{1,2}$ G. C. Hadjipanayis, ${ }^{3}$ and D. J. Sellmyer ${ }^{1,2}$ \\ ${ }^{1}$ Nebraska Center for Materials and Nanoscience, University of Nebraska, Lincoln, Nebraska 68588, USA \\ ${ }^{2}$ Department of Physics and Astronomy, University of Nebraska, Lincoln, Nebraska 68588, USA \\ ${ }^{3}$ Department of Physics and Astronomy, University of Delaware, Newark, Delaware 19716, USA
}

(Presented 31 October 2011; received 21 September 2011; accepted 16 November 2011; published online 7 March 2012)

\begin{abstract}
Sm-Co bulk alloys have shown superior permanent-magnet properties, but research on Sm-Co nanoparticles is challenging because of the need to control particle size, size-distribution, crystalline ordering, and phase purity. In the present study, a cluster-deposition method was used to produce $\mathrm{Sm}$-Co nanoparticles having desired crystal structures without the requirement of subsequent high-temperature thermal annealing. Poorly crystallized $\mathrm{SmCo}_{5}$ nanoparticles exhibit a low room-temperature coercivity of only $100 \mathrm{Oe}$, whereas crystalline $\mathrm{SmCo}_{5}$ and $\mathrm{Sm}_{2} \mathrm{Co}_{17}$ nanoparticles show room-temperature coercivities of 2000 and 750 Oe, respectively. The direct synthesis of Sm-Co nanoparticles having sizes of less than $10 \mathrm{~nm}$ and a high degree of atomic ordering is an important step toward creating nanoparticle building blocks for permanent-magnets and other significant applications. (C) 2012 American Institute of Physics. [doi:10.1063/1.3677668]
\end{abstract}

Bulk Sm-Co alloys have long been valued in permanent magnetism, especially $\mathrm{SmCo}_{5}$ and $\mathrm{Sm}_{2} \mathrm{Co}_{17}$, which crystallize in the hexagonal $\mathrm{CaCu}_{5}$ and rhombohedral $\mathrm{Th}_{2} \mathrm{Zn}_{17}$-type structures, respectively. ${ }^{1-3}$ These materials exhibit high roomtemperature magnetic anisotropy constants $\left(K_{1}\right)$, namely $22 \times 10^{7} \mathrm{ergs} / \mathrm{cm}^{3}\left(\mathrm{SmCo}_{5}\right)$ and $3 \times 10^{7} \mathrm{ergs} / \mathrm{cm}^{3}\left(\mathrm{Sm}_{2} \mathrm{Co}_{17}\right)$, along with high Curie temperatures $\left(T_{\mathrm{c}}>1020 \mathrm{~K}\right)$ and appreciable magnetic polarizations $\left(J_{s}>10 \mathrm{kG}\right) .^{3,4}$ The research on $\mathrm{Sm}-\mathrm{Co}$ nanoparticles is, however, challenged by the requirement of high-temperature annealing above $800^{\circ} \mathrm{C}$ for alloy formation and crystalline ordering, which results in poor control of size, size-distribution, and phase purity. ${ }^{5-8}$

$\mathrm{SmCo}_{5}$ and $\mathrm{Sm}_{2} \mathrm{Co}_{17}$ nanoparticles have previously been prepared by surfactant-assisted ball milling of bulk Sm-Co alloys, but these nanoparticles show a very low room-temperature coercivity of $\leq 100$ Oe and a substantial reduction of magnetization due to the presence of surfactants, incomplete ordering, and oxidation. ${ }^{5}$ In addition, ball milling process induces strains and amorphorization and also leads to the decomposition of the Sm-rich $\mathrm{SmCo}_{5}$ phase. ${ }^{8}$ Low-temperature wet chemical polyol process at about $270{ }^{\circ} \mathrm{C}$ using $\mathrm{Co}$ and $\mathrm{Sm}$ metal precursors in the presence of tetraethylene glycol resulted in $\mathrm{SmCo}_{5}$ nanoparticles of particle sizes less than $20 \mathrm{~nm}$ with room temperature coercivities in the range of 100 to 1500 Oe. ${ }^{6,7}$ Recently, the reduction of $\mathrm{Sm}$ (III) and $\mathrm{Co}$ (II) salts in tetraethylene glycol has been found to yield predominant $\mathrm{Co}_{2} \mathrm{C}$ phase with $\mathrm{X}$-diffraction peaks similar to $\mathrm{SmCo}_{5} \cdot{ }^{9,10}$ Our recent work on plasma-condensation-type cluster deposition, performed under high-vacuum conditions, has been shown to reduce rare-earth oxidation and to produce single-phase and crystalline $\mathrm{YCo}_{5}$ and $\mathrm{Y}_{2} \mathrm{Co}_{17}$ nanoparticles without any hightemperature thermal annealing. ${ }^{11}$

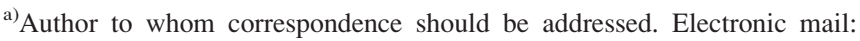
bbalasubramanian2@unl.edu.
}

In the present study, Sm-Co nanoparticles with different stoichiometries, especially $\mathrm{SmCo}_{5}$ and $\mathrm{Sm}_{2} \mathrm{Co}_{17}$, were produced using a cluster deposition. The experimental setup consists of a cluster-formation chamber having a direct current (DC) magnetron plasma-sputtering discharge with a watercooled gas-aggregation tube and a deposition chamber, where the substrate is kept at room temperature. ${ }^{11,12}$ An Sm-Co composite target was sputtered using a mixture of Ar and $\mathrm{He}$ as sputtering gases to form Sm-Co nanoparticles in the gasaggregation chamber, which were extracted as a collimated beam traveling toward the substrate in the deposition chamber. The desired stoichiometry and crystalline ordering were directly obtained during the aggregation process by controlling the DC magnetron sputtering power $\left(P_{d c}=100\right.$ $-200 \mathrm{~W}$ ), prior to deposition on suitable substrates. Sm-Co nanoparticles were deposited on single crystalline Si (001) substrates for SQUID magnetometer, energy dispersive x-ray analysis (EDX), and X-ray diffraction (XRD: Rigaku $\mathrm{D} /$ Max-B diffractometer, $\mathrm{Cu} \mathrm{K} \alpha$ with $\lambda=1.5418 \AA$ ) studies and on carbon coated copper grids for transmission electron microscopy (TEM: JEOL 2010 with an acceleration voltage of $200 \mathrm{kV}$ ) measurement.

The compositions and crystal structures of as-produced Sm-Co nanoparticles deposited at different $P_{d c}$ were evaluated using EDX and XRD measurements, respectively. EDX analysis yields compositions corresponding to $\mathrm{SmCo}_{5}$ for 100 $\leq P_{d c} \leq 160 \mathrm{~W}$ and $\mathrm{Sm}_{2} \mathrm{Co}_{17}$ for $180 \leq P_{d c} \leq 200 \mathrm{~W}$ (not shown here). The crystalline ordering of these nanoparticles also strongly depends on $P_{d c}$, as shown in the XRD patterns of Fig. 1, which include the standard positions and relative intensities of diffraction peaks corresponding to hexagonal $\mathrm{CaCu}_{5}$ (blue vertical-solid lines) and rhombohedral $\mathrm{Th}_{2} \mathrm{Zn}_{17}$-type (red vertical-dotted lines). ${ }^{13,14}$ Note that the maximum intensity diffraction peak corresponding to both the structures appears at angles of $2 \theta=39^{\circ}-45^{\circ}$ as revealed by the standard data. 


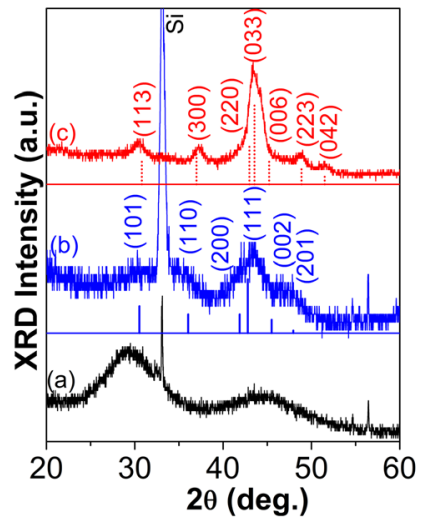

FIG. 1. (Color online) XRD patterns of Sm-Co nanoparticles prepared at different sputtering powers $\left(P_{d c}\right)$ : (a) $\mathrm{SmCo}_{5}\left(P_{d c}=100 \mathrm{~W}\right)$, (b) $\mathrm{SmCo}_{5}$ $\left(P_{d c}=160 \mathrm{~W}\right)$, and $(\mathrm{c}) \mathrm{Sm}_{2} \mathrm{Co}_{17}\left(P_{d c}=200 \mathrm{~W}\right)$. The standard peak positions corresponding to the hexagonal $\mathrm{CaCu}_{5}$ (blue solid-vertical lines) and rhombohedral $\mathrm{Th}_{2} \mathrm{Zn}_{17}$ (red dotted-vertical lines) structures are also given.

The XRD pattern of the as-produced $\mathrm{SmCo}_{5}$ nanoparticles deposited at a low $P_{d c}$ of $100 \mathrm{~W}$ shows only a broad and weak diffraction peak in the higher-angle region, along with another broad peak in the lower-angle region $\left(2 \theta=23^{\circ}\right.$ $-36^{\circ}$ ), and thus reveals a poor crystalline ordering in these nanoparticles, as noted in Fig. 1(a). On increasing $P_{d c}=160$ $\mathrm{W}$, the diffraction peaks corresponding to $\mathrm{CaCu}_{5}$ become visible and intense at higher angles, as noted in Fig. 1(b), revealing the improvement in the crystalline ordering. However, the XRD pattern of as-produced $\mathrm{Sm}_{2} \mathrm{Co}_{17}$ nanoparticles deposited at a high $P_{d c}$ of $200 \mathrm{~W}$ has intense and sharp diffraction peaks, which are in good agreement with the standard diffraction lines corresponding to the rhombohedral $\mathrm{Th}_{2} \mathrm{Zn}_{17}$-type structure, as noted in Fig. 1(c).

Note that some of the diffraction peaks separated by only a small angular position are indistinguishable, Figs. $1(\mathrm{~b})$ and 1(c), because they have broad peaks resulting from their nanoparticle nature. The average particle size and size distribution of the $\mathrm{Sm}$-Co nanoparticles were investigated using TEM. For example, the TEM micrograph of Fig. 2(a) and the corresponding particle-size histogram of $\mathrm{SmCo}_{5}$ nanoparticles prepared at $P_{d c}=160 \mathrm{~W}$ exhibit an average particle size (d in Fig. 2(a)) of $8.4 \mathrm{~nm}$ and an rms standard deviation of $\alpha / d \simeq 0.20 . \mathrm{Sm}_{2} \mathrm{Co}_{17}$ nanoparticles deposited at a high power of $200 \mathrm{~W}$ exhibit an average particle size $d \simeq 10.8 \mathrm{~nm}$ with $\alpha / d \simeq 0.19$ (Fig. 2(b)).

This study revealed a direct crystalline ordering of SmCo nanoparticles during the cluster-aggregation process by varying $P_{d c}$ without subsequent high-temperature thermal annealing. However, Sm-Co intermetallics are characterized by small enthalpy differences per atom, as exemplified by $\mathrm{SmCo}_{5}(-6.8 \mathrm{~kJ} / \mathrm{mol})$ and $\mathrm{Sm}_{2} \mathrm{Co}_{17}(-8.0 \mathrm{~kJ} / \mathrm{mol})$, and require a complicated heat treatment for alloy formation and crystalization. ${ }^{15}$ In the present study, a high $P_{d c} \geq 160 \mathrm{~W}$ is expected to result in highly energetic and dense ions in the gas aggregation region, which leads to an increase in clusterion collision probability and subsequently provides sufficient energy for crystallization. ${ }^{16}$

The magnetic properties of Sm-Co nanoparticles were investigated by measuring the magnetization $M$ as a function
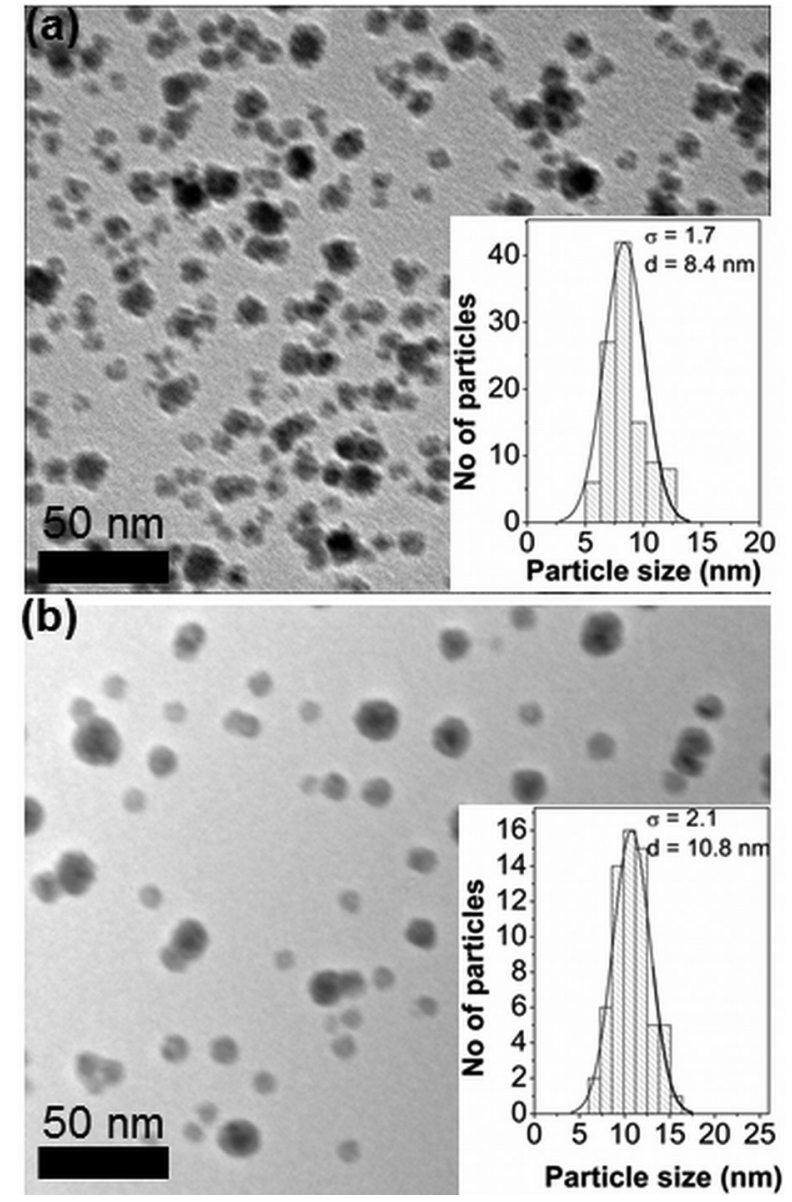

FIG. 2. Transmission electron microscope images of the cluster-deposited (a) $\mathrm{SmCo}_{5}$ and (b) $\mathrm{Sm}_{2} \mathrm{Co}_{17}$ nanoparticles, whereas the corresponding particle size histograms are given as an inset. $\sigma$ and $\mathrm{d}$ are the standard deviation and average particle size, respectively.

of applied magnetic field $H$ at 300 and $10 \mathrm{~K}$. Figure 3 shows room-temperature hysteresis loops for $\mathrm{Sm}$-Co nanoparticles prepared at different $P_{d c}$. Poorly crystalline $\mathrm{SmCo}_{5}$ nanoparticles prepared at $P_{\mathrm{dc}}=100 \mathrm{~W}$ exhibit a very low coercivity $\left(H_{c}\right)$ of $100 \mathrm{Oe}$ and a remanence ratio of $M_{r} / M_{s}=0.23$ at $300 \mathrm{~K}$, as noted in Fig. 3(a), where $M_{r}$ and $M_{s}$ are the remanent and saturation magnetizations, respectively. The softmagnetic behavior in these nanoparticles is caused by reduced magnetocrystalline anisotropy due to the poor crystallinity.

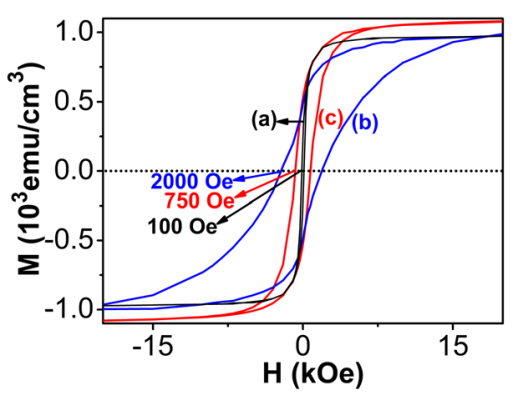

FIG. 3. (Color online) Room-temperature hysteresis loops for (a) poorly crystallized $\mathrm{SmCo}_{5}$, (b) crystalline $\mathrm{SmCo}_{5}$ and (c) crystalline $\mathrm{Sm}_{2} \mathrm{Co}_{17}$ nanoparticles prepared at different sputtering powers of 100, 160, and $200 \mathrm{~W}$, respectively. 


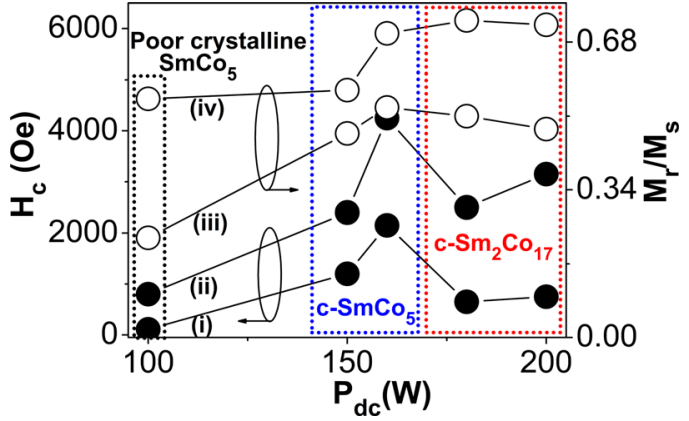

FIG. 4. (Color online) Magnetic properties of Sm-Co nanoparticles as a function of DC magnetron sputtering power $P_{\mathrm{dc}}$ : Coercivities $\left(H_{\mathrm{c}}\right)$ at (i) $300 \mathrm{~K}$ and (ii) $10 \mathrm{~K}$ and remanence ratios $\left(M_{r} / M_{s}\right)$ at (iii) 300 and (iv) $10 \mathrm{~K}$.

Crystalline $\mathrm{SmCo}_{5}$ nanoparticles deposited at $P_{\mathrm{dc}}=160 \mathrm{~W}$ exhibit hard-magnetic properties with $H_{c}=2000$ Oe and $M_{r} / M_{s}=0.53$ at $300 \mathrm{~K}$, as noted in Fig. 3(b). Crystalline $\mathrm{Sm}_{2} \mathrm{Co}_{17}$ nanoparticles deposited at a large $P_{\mathrm{dc}}=200 \mathrm{~W}$ are softer, with $H_{c}=750 \mathrm{Oe}$ and $M_{r} / M_{s}=0.48$, as presented in Fig. 3(c). This can be attributed to the anisotropy constant of $\mathrm{Sm}_{2} \mathrm{Co}_{17}$, which is one order smaller than that of $\mathrm{SmCo}_{5}{ }^{3}$ Fig. 3 also shows that crystalline $\mathrm{SmCo}_{5}$ and $\mathrm{Sm}_{2} \mathrm{Co}_{17}$ nanoparticles exhibit high $J_{s}$ of 11.1 and $13.8 \mathrm{kG}$, respectively, which is similar to bulk. As summarized in Fig. 4, the magnetic properties of clusterdeposited Sm-Co nanoparticles measured at 300 and $10 \mathrm{~K}$ strongly depend on $P_{d c}$. $H_{c}$ and $M_{r} / M_{s}$ of Sm-Co nanoparticles are enhanced at $10 \mathrm{~K}$ as shown in Fig. 4.

$\mathrm{Sm}$-Co nanostructures are known to exhibit a strong dependence of room-temperature coercivity on particle size. ${ }^{8,17}$ $H_{c}$ reaches a maximum value for a critical particle size and a further decrease in size leads to a decrease in $H_{c}$. This behavior has been attributed due to complex effects of crystalline ordering, surface morphology, and size-induced thermal fluctuations. ${ }^{8,17,18}$ Note that room-temperature coercivities of crystalline $\mathrm{SmCo}_{5}$ and $\mathrm{Sm}_{2} \mathrm{Co}_{17}$ nanoparticles are in good agreement with the previously reported size-effects on the coercivity of Sm-Co. ${ }^{8,17}$

In conclusion, crystalline $\mathrm{SmCo}_{5}$ and $\mathrm{Sm}_{2} \mathrm{Co}_{17}$ nanoparticles were directly produced using a plasma-condensation-type cluster-deposition method without subsequent high-temperature thermal annealing. The Sm-Co nanoparticles gain sufficient energy from the inert gas ions during the gas-aggregation process for crystallization. $\mathrm{SmCo}_{5}$ nanoparticles show compara- tively hard magnetic properties with coercivities of 2000 and $4250 \mathrm{Oe}$ at 300 and $10 \mathrm{~K}$, respectively. The direct ordering of $\mathrm{Sm}$-Co nanoparticles prior to deposition is important for assembling nanoparticle building blocks for practical applications.

\section{ACKNOWLEDGMENTS}

This work is supported by US Department of Energy (Grant No. DE-FG02-04ER46152, D.J.S., Advanced Research Projects Agency-Energy (Grant No. DE-AR 0000046, B.B. and G.C.H.), NSF-Materials Research Science and Engineering Center (Grant \# DMR-0820521, R.S.), and Nebraska Center for Materials and Nanoscience (X.Z.L). Thanks are due to Zhiquang Sun for his technical assistance and Shah R. Valloppilly and Bhaskar Das for helpful discussions.

${ }^{1}$ K. Strnat, G. Hoffer, J. Olson, W. Ostertag, and J. J. Becker, J. Appl. Phys. 38, 1001 (1967)

${ }^{2}$ M. Yue, J. H. Zuo, W. Q. Liu, W. C. Lv, D. T. Zhang, J. X. Zhang, Z. H. Guo, and W. Li, J. Appl. Phys. 109, 07A711 (2011).

${ }^{3}$ R. Skomski, J. Phys. : Condens. Matter. 15, R841 (2003).

${ }^{4}$ J. Sayama, K. Mizutani, T. Asahi, and T. Osaka, Appl. Phys. Lett. 85, 5640 (2004).

${ }^{5}$ V. M. Chakka, B. Altuncevahir, Z. Q. Jin, and J. P. Liu, J. Appl. Phys. 99, 08E912 (2006).

${ }^{6}$ T. Matsushita, T. Iwamoto, M. Inokuchi, and N. Toshima, Nanotechnology 21, 095603 (2010).

${ }^{7}$ P. Saravanan, G. V. Ramana, K. S. Rao, B. Sreedhar, V. T. P. Vinod, and V. Chandrasekaran, J. Magn. Magn. Mater. 323, 2083 (2011).

${ }^{8}$ N. Poudyal, C. Rong, and J. P. Liu, J. Appl. Phys. 107, 09A703 (2011).

${ }^{9}$ C. N. Chinnasamy, J. Y. Huang, L. H. Lewis, B. Latha, C. Vittoria, and V. G. Harris, Appl. Phys. Lett. 93, 032505 (2008).

${ }^{10}$ C. N. Chinnasamy, J. Y. Huang, L. H. Lewis, B. Latha, C. Vittoria, and V. G. Harris, Appl. Phys. Lett. 97, 059901 (2010).

${ }^{11}$ B. Balasubramanian, R. Skomski, X. Z. Li, S. R. Valloppilly, J. E. Shield, G. C. Hadjipanayis, and D. J. Sellmyer, Nano Lett. 11, 1747 (2011).

${ }^{12}$ B. Balamurugan, R. Skomski, and D. J. Sellmyer, Magnetic Clusters and Nanoparticles in Nanoparticles: Synthesis, Characterization, and Applications, edited by R. S. Chaughule and R. V. Ramanujan (American Scientific Publishers, California, 2010) p. 127.

${ }^{13}$ ICDD- 2011 International Centre for Diffraction Data, Card No. 01-0752837.

${ }^{14}$ ICDD- 2011 International Centre for Diffraction Data, Card No. 04-0011105.

${ }^{15}$ F. Meyer-Liautaud, C. H. Allibert, and R. Castanet, J. Less-Common Met. 127, 243 (1987).

${ }^{16}$ M. M. Patterson, A. Cochran, J. Ferina, X. Rui, T. A. Zimmerman, Z. Sun, D. J. Sellmyer, and J. E. Shield, J. Vac. Sci. Technol. B 28, 273 (2010).

${ }^{17}$ C. H. Chen, S. J. Knutson, Y. Shen, R. A. Wheeler, J. C. Horwath, and P. N. Barnes, Appl. Phys. Lett. 99, 012504 (2010).

${ }^{18}$ E. F. Kneller and F. E. Luborsky, J. Appl. Phys. 34, 656 (1963). 